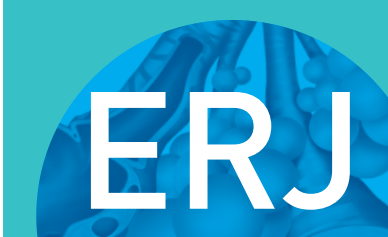

open research
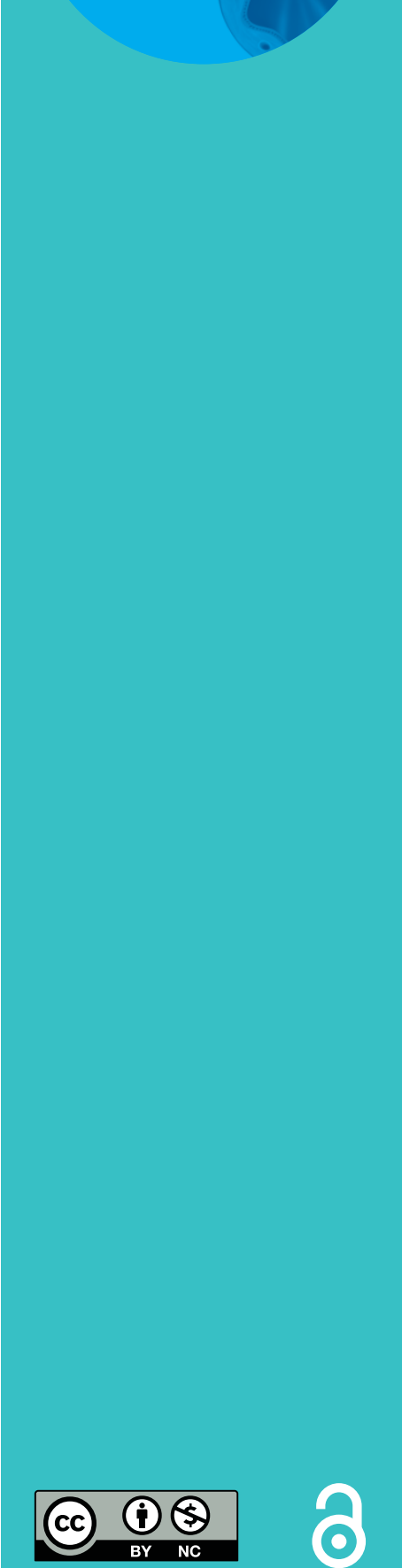

\section{Tossing and turning: association of sleep quantity-quality with physical activity in COPD}

\author{
Raquel Pastrello Hirata ${ }^{1}$, Daniele Caroline Dala Pola ${ }^{1}$, Lorena Paltanin Schneider ${ }^{1}$, \\ Mariana Pereira Bertoche ${ }^{1}$, Karina Couto Furlanetto (1) ${ }^{1,2}$, \\ Nidia Aparecida Hernandes ${ }^{1}$, Arthur Eumann Mesas ${ }^{3,4}$ and Fabio Pitta (1) ${ }^{1}$
}

Affiliations: 'Laboratory of Research in Respiratory Physiotherapy, Dept of Physiotherapy, State University of Londrina (UEL), Londrina, Brazil. ${ }^{2}$ Research Center in Health Sciences, University of Northern Paraná (UNOPAR), Londrina, Brazil. ${ }^{3}$ Postgraduate Program in Public Health, UEL, Londrina, Brazil. ${ }^{4}$ Health and Social Research Center, Universidad de Castilla-La Mancha, Cuenca, Spain.

Correspondence: Fabio Pitta, Departamento de Fisioterapia - CCS, Hospital Universitário de Londrina, Avenida Robert Koch, 60 - Vila Operária, 86038-350 Londrina, Paraná, Brazil. E-mail: fabiopittaQuol.com.br

ABSTRACT The association between characteristics of sleep and physical activity in daily life (PADL) has not yet been investigated in depth in subjects with COPD. This study evaluated whether time spent per day in physical activity (PA) and sedentary behaviour are associated with sleep quantity and quality in this population.

Sleep and PADL were objectively assessed by an activity monitor for 7 days and analysed on a minuteby-minute basis. Subjects also underwent spirometry and 6-min walking test (6MWT).

Fifty-five subjects with moderate-to-severe COPD (28 male, $67 \pm 8$ years) were studied. Subjects with total time in bed (TIB) per night $\geqslant 9 \mathrm{~h}$ had higher wake-after-sleep onset than TIB $7-9 \mathrm{~h}$ and TIB $\leqslant 7 \mathrm{~h}$ (195 (147-218) versus $117(75-167)$ and $106(84-156) \mathrm{min})$ and more fragmented sleep than TIB $\leqslant 7 \mathrm{~h}$ (8.2 (6.7-14.3) versus 6.3 (5.6-6.9) sleeping bouts; $\mathrm{p}<0.05$ for all). Subjects with TIB $\geqslant 9 \mathrm{~h}$ also spent more time per day in sedentary behaviour and less time per day in PA of light and moderate-to-vigorous intensity than those with TIB $7-9 \mathrm{~h}$ and $\leqslant 7 \mathrm{~h}$. In multiple linear regression, TIB $\geqslant 9 \mathrm{~h}$ was the only significant predictor of physical inactivity $(\beta=-3.3(-5.1,-1.6), p \leqslant 0.0001)$, accounting for $20 \%$ of its variation. Sleep fragmentation was frequent and more pronounced in physically inactive than active patients (7.5 (6.3-9.6) versus 6.4 (5.5-7.3) sleeping bouts; $\mathrm{p}=0.027)$.

In summary, subjects with COPD with TIB $\geqslant 9 \mathrm{~h} \cdot$ night $^{-1}$ have more fragmented sleep, are more sedentary and less physically active than those with $<9 \mathrm{~h} \cdot$ night $^{-1}$, independently of the awake time. Sleep quality is frequently poor and even worse in patients classified as physically inactive.

@ERSpublications

This study shows, for the first time, that sleep quantity is a determinant factor of objectively assessed level of physical activity in subjects with COPD https://bit.ly/3diOIlC

Cite this article as: Hirata RP, Dala Pola DC, Schneider LPaltanin, et al. Tossing and turning: association of sleep quantity-quality with physical activity in COPD. ERJ Open Res 2020; 6: 003702020 [https://doi.org/10.1183/23120541.00370-2020].

This article has supplementary material available from openres.ersjournals.com.

Received: 11 June 2020 | Accepted after revision: 5 Oct 2020

Copyright $\odot$ ERS 2020. This article is open access and distributed under the terms of the Creative Commons Attribution Non-Commercial Licence 4.0. 


\section{Introduction}

COPD is a common disease characterised by systemic consequences beyond respiratory impairment [1]. There is consistent evidence showing that physical activity in daily life (PADL) is markedly reduced and considered an independent predictor of mortality in patients with COPD [2-4]. More recently, in addition to physical inactivity, there has been increasing interest in also studying sedentary behaviour in patients with COPD. Evidence shows that sedentary behaviour is clearly different than physical inactivity, and when present adds an extra burden to the patient's clinical condition [5]. Physical inactivity is defined as not achieving at least $30 \mathrm{~min} \cdot \mathrm{day}^{-1}$ of moderate-to-vigorous physical activity (MVPA) for at least 5 days of the week, or $20 \mathrm{~min} \cdot \mathrm{day}^{-1}$ of vigorous activities for at least 3 days of the week; while sedentary behaviour can be defined as any waking behaviour characterised by an energy expenditure $\leqslant 1.5$ metabolic equivalents of task (METs) [6,7]. Sedentary time is also an independent predictor of mortality in subjects with COPD, even after adjusting for MVPA and a number of other variables [8]. For these reasons, there is great interest in understanding what are the factors related to physical inactivity and sedentary behaviour in individuals with COPD, in order to optimise strategies to overcome these negative features of the disease.

A good night's sleep is well recognised as closely related to physical and mental health. In terms of quantity, the leading sleep organisations recommend a minimum of $7 \mathrm{~h}$ of sleep; however, there is evidence of a U-shaped relationship between sleep duration and health-related outcomes, showing that spending more than $9 \mathrm{~h}$ in bed is associated with higher morbidity and mortality in adults and older adults $[9,10]$. In terms of sleep quality, although this is a term widely used in the literature, there is a lack of consensus about its definition and how it should be measured. As an attempt of standardisation, the National Sleep Foundation recently published a guidance report with the most recommended parameters to measure sleep quality. Besides the amount of time spent at different sleep stages, outcomes such as sleep efficiency, awakenings and wake time after sleep onset (WASO) were selected as good indicators for the measurement of sleep quality [11]. Actigraphy is a useful tool which is able to provide objective estimates of sleep/wake parameters similar to polysomnography and to bring more reliable information about sleep quantity and fragmentation than subjective evaluations [12]. Poor sleep quality is frequently reported in COPD [13-15] and is related to higher rates of exacerbation and hospitalisation [16-18]. Furthermore, there is evidence showing that poor sleep quality is associated with impairment of quadriceps muscle strength, exercise capacity and PADL [19-21]. For instance, in terms of PADL, patients with better sleep measures (i.e. nonfragmented sleep, longer sleeping bouts, higher sleep efficiency and lower time spent awake after sleep onset) spend significantly more time in MVPA in the following day [19]. However, despite its apparent importance, the relationship between sleep and movement-related behaviour in real life in COPD has not yet been studied in depth [22]. Therefore, the aim of the study was to evaluate whether time spent in physical activity and in sedentary behaviour are associated with sleep quantity and quality in this population.

\section{Methods}

This was a cross-sectional analysis with retrospective data from a convenience sample of patients evaluated in the Laboratory of Research in Respiratory Physiotherapy, State University of Londrina, Brazil. Subjects enrolled in these baseline-only analyses took part later in an unrelated longitudinal study [23]. This study was approved by the local ethical committee (no. 123/09) and written informed consent was obtained from all participants. Inclusion criteria were the diagnosis of COPD according to the Global Initiative for Chronic Obstructive Lung Disease (GOLD) [1], stable condition (no exacerbations/infections in the preceding 3 months), and absence of severe/unstable cardiac disease and comorbidities that could influence the assessments. Exclusion criterium was not achieving the minimum wearing time for the activity monitoring assessments, as further described below.

\section{Assessments}

Physical activity, sedentary behaviour and sleep were objectively assessed by the multisensory activity monitor SenseWear ${ }^{\oplus}$ Pro2 Armband (BodyMedia, Pittsburgh, USA), worn on the upper-posterior region of the right arm $[24,25]$. This monitor has been previously used to study sleep in COPD and is often used also in patients with obstructive sleep apnoea $[19,26]$. Patients were instructed to wear the monitor for $24 \mathrm{~h}$ during 7 consecutive days and nights. A minimum on-body time of $22 \mathrm{~h} \cdot$ day $^{-1}$ was considered as a valid assessment day, and the activity monitor should be worn for at least 4 valid assessment days. The following sleep variables were determined: total time in bed (TIB) (i.e. total time spent lying in bed for sleep during the night); total sleep time (TST) (i.e. total time classified as "sleep" during the TIB); sleep efficiency (i.e. proportion of TST in relation to TIB); WASO (i.e. total time measured as "awake" during the TIB); and sleeping bouts number and duration (i.e. amount and average duration of blocks of minutes measured as "sleep" with no interruptions). PADL was evaluated considering the remaining awake time (excluding total 
time spent in bed during the night and any sleep (i.e. nap during the day). Time spent per day in sedentary behaviour (i.e. activities demanding $\leqslant 1.5 \mathrm{METs}$ ), light intensity physical activity ((LIPA) 1.5-2.9 METs) and MVPA ( $\geqslant 3$ METs) were categorised in a minute-by-minute basis, as well as the number of steps.day ${ }^{-1}$ and total energy expenditure. Results of PADL and sleep for each patient were averaged (as per day) taking into account the valid assessment days of that subject. Patients were classified in three groups based on the TIB $(\leqslant 7 \mathrm{~h}, 7-9 \mathrm{~h}, \geqslant 9 \mathrm{~h}$ ) according to the recommendations of sleep quantity from the National Sleep Foundation [9]. Although not a synonym of TST, it is emphasised that the time spent in bed for sleep at night was considered to reflect sleep quantity as well as to separate the groups based on hours of sleep. Therefore, for convenience, the term sleep quantity was used throughout the paper.

Patients also underwent assessments of pulmonary function [27, 28], 6-min walking test (6 MWT) [29, 30], and body composition [31] according to international recommendations (see online supplement for details). Fat-free mass (FFM) was calculated from bioelectrical impedance using a specific formula derived for patients with COPD [32]. Fat-free mass index (FFMI) was calculated by dividing FFM by height squared $\left(\mathrm{m}^{2}\right)$.

\section{Statistical analysis}

Data distribution was assessed using Shapiro-Wilk test and described as mean \pm SD or median (interquartile range) when appropriate. Chi-squared test was used to compare categorical variables. A Mann-Whitney U-test or Kruskal-Wallis test was used to compare two or three groups, respectively; and Bonferroni was used for post hoc analysis, when necessary. Stepwise multiple linear regression models were applied to predict the time spent per day in physical activity ( $>1.5 \mathrm{METs})$ and in sedentary behaviour ( $\leqslant 1.5 \mathrm{METs}$ ) by attempting different variables of sleep quantity and quality, and also including pulmonary function, dyspnoea, and 6 MWT. Data were analysed using IBM SPSS Statistics ${ }^{\mathrm{TM}} 21.0$ (IBM, Chicago, USA) and a $\mathrm{p}<0.05$ was considered significant.

\section{Results}

Fifty-eight patients were included and three were excluded due to not reaching the minimum number of valid assessment days in the activity monitoring. The analysed sample comprised 55 patients who used the activity monitor for a mean of $6.78 \pm 0.6$ days during $23.3 \pm 0.4 \mathrm{~h} \cdot$ day $^{-1}$. The sample was characterised by patients presenting moderate to very severe disease, who were quite symptomatic and mostly sedentary during the day (table 1). They were in use of a median (interquartile range) of $3(2-5)$ medications at the time of the assessment $(n=46): 34(74 \%)$ of the patients were in use of adrenergic agonists, 17 (37\%) of them in use of muscarinic blockers and $28(61 \%)$ in use of corticosteroids.

\section{Quantity and quality of sleep versus physical activity in daily life}

In general, patients lay in bed to sleep at 23:03 h $(22: 17-23: 50 \mathrm{~h})$ and got out of bed at $07: 10 \mathrm{~h}$ (06:36-08:02 h). TST was positively associated with TIB $(\mathrm{r}=0.65, \mathrm{p}<0.0001)$, with patients spending an average of $5.5 \mathrm{~h}$ sleeping from $8.1 \mathrm{~h}$ lying in bed. The median value of sleeping bouts was 6.9 per night, and the number of sleeping bouts was inversely associated with sleeping bouts duration $(r=-0.72$, $\mathrm{p}<0.0001)$. Patients classified as inactive [7] presented higher number of sleeping bouts than those classified as active (7.5 (6.3-9.6) versus 6.4 (5.5-7.3); $\mathrm{p}=0.027)$. Patients with higher sleep fragmentation (i.e. $>6.9$ bouts of sleep) presented less time spent in LIPA than those with lower sleep fragmentation (40 (27-46) versus 29 (19-36) \% $\mathrm{T}_{\text {awake, }} \mathrm{p}=0.040$; see online supplement, table $\mathrm{S} 1$ ).

Table 2 shows that when comparing patients regarding sleep quantity, those who spent more than $9 \mathrm{~h}$ lying in bed $($ TIB $\geqslant 9 \mathrm{~h}$ ) presented a more fragmented sleep and spent more time awake during the time they intended to sleep. This same group presented a significantly lower time spent in LIPA and MVPA (minutes), as well as a lower number of steps.day ${ }^{-1}$ when compared to groups TIB $\leqslant 7 \mathrm{~h}$ and TIB $7-9 \mathrm{~h}$. As the duration of awake time was different among groups, we also compared PADL expressed as a percentage of time awake. The proportion of time spent awake in sedentary behaviour was significantly higher in patients with TIB $\geqslant 9 \mathrm{~h}$, and the proportion of time spent awake in LIPA and MVPA was significantly lower in this group when compared to groups TIB $\leqslant 7 \mathrm{~h}$ and TIB $7-9 \mathrm{~h}$ (figure 1 ). Concerning the number of medications in use or the distribution of the different types of these medications (adrenergic agonists, muscarinic blockers and/or corticosteroids), there were no differences among groups.

Results from the stepwise regression model showed that, among the independent variables studied, TIB $\geqslant 9 \mathrm{~h}$ was the only significant predictor of time spent in physical activity $(\beta=-3.3(-5.1,-1,6), \mathrm{p} \leqslant 0.0001)$, accounting for $20 \%$ of its variation. It was not possible to predict time spent in sedentary behaviour as no model yielded any significant result by using the same independent variables. 


\begin{tabular}{|c|c|}
\hline Variables & $n=55$ \\
\hline Male sex $n(\%)$ & $28(51)$ \\
\hline Age years & $67 \pm 8$ \\
\hline FEV $1 \%$ pred & $55(38-62)$ \\
\hline GOLD $1 / 2 / 3 / 4$ n $(\%)$ & $1(2) / 34(62) / 11(20) / 9(16)$ \\
\hline mMRC $0 / 1 / 2 / 3 / 4$ n $(\%)$ & $6(11) / 11(20) / 9(16) / 23(42) / 6(11)$ \\
\hline HADS anxiety score & $5(1.5-7)$ \\
\hline HADS depression score & $3(1-6)$ \\
\hline BMI $\mathrm{kg} \cdot \mathrm{m}^{-2}$ & $26 \pm 5$ \\
\hline FFMI $\mathrm{kg} \cdot \mathrm{m}^{-2}$ & $19.8 \pm 2.2$ \\
\hline $\mathrm{FMI} \mathrm{kg} \cdot \mathrm{m}^{-2}$ & $6.2 \pm 3.8$ \\
\hline 6MWT m & $473 \pm 75$ \\
\hline Hypertension n (\%) & $28(51)$ \\
\hline Diabetes n $(\%)$ & $12(22)$ \\
\hline Heart disease $n(\%)$ & $9(16)$ \\
\hline \multicolumn{2}{|l|}{ Sleep characteristics } \\
\hline TIB h & $8.1 \pm 1.3$ \\
\hline TST h & $5.5 \pm 1.3$ \\
\hline Sleep efficiency \% & $69 \pm 13$ \\
\hline Sleeping bouts $\mathrm{n}$ & $6.9(5.9-8.2)$ \\
\hline Sleeping bouts duration min & $50(39-67)$ \\
\hline WASO min & $138 \pm 63$ \\
\hline \multicolumn{2}{|l|}{ PADL characteristics } \\
\hline Awake time $\mathrm{h}$ & $14.8 \pm 1.8$ \\
\hline Time spent in SB min $\left(\% \mathrm{~T}_{\text {awake }}\right)$ & $537 \pm 151(61 \pm 18)$ \\
\hline Time spent in LIPA min $\left(\% \mathrm{~T}_{\text {awake }}\right)$ & $291 \pm 143(32 \pm 14)$ \\
\hline Time spent in MVPA min $\left(\% \mathrm{~T}_{\text {awake }}\right)$ & $37(10-94)(5(1-11))$ \\
\hline Steps $\cdot$ day $^{-1} \mathrm{n}$ & $7118 \pm 4081$ \\
\hline Total energy expenditure $\cdot \mathrm{day}^{-1} \mathrm{kcal}$ & 1540 (1253-1725) \\
\hline Average MET.day ${ }^{-1}$ & $1.6 \pm 0.3$ \\
\hline \multicolumn{2}{|c|}{ 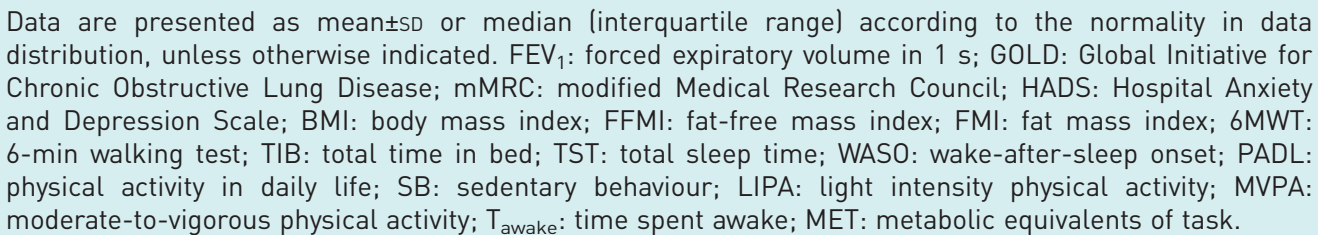 } \\
\hline
\end{tabular}

\section{Quantity and quality of sleep between males and females}

Although not statistically significant, the proportion of male subjects was $64 \%$ in the higher sleep fragmentation group and $37 \%$ in the lower sleep fragmentation group, respectively (see table S1 for details). Moreover, figure 2 illustrates that, despite the absence of significant difference in TIB between males and females (491 (430-537) versus 476 (422-533), respectively; $\mathrm{p}=0.814$ ), sleep quality was significantly worse for males compared to females, as follows: TST (313 (253-362) versus 368 (304-392) min; $\mathrm{p}=0.045)$, sleep efficiency (65 (57-73) versus 74 (69-82); $\mathrm{p}=0.003)$, WASO (167 (121-202) versus 105 (67-144) min; $\mathrm{p}=0.002)$, number of sleeping bouts $(7.3$ (6.4-9.6) versus $6.2(4.5-7.5) ; \mathrm{p}=0.016)$, and sleeping bouts duration (41 (34-56) versus 60 (48-85) $\mathrm{min} ; \mathrm{p}=0.006)$. There were no between-sex differences regarding age, body mass index, COPD severity, exercise capacity and PADL.

\section{Discussion}

This study describes a novel finding that not only quality but also quantity of sleep are important issues that could affect the level of PADL in patients with COPD. Firstly, patients who spent 9 or more h.night ${ }^{-1}$ lying in bed for sleep actually had worse sleep quality, worse level of physical activity and spent approximately $20 \%$ more time in sedentary behaviour during awake time than patients who spent less TIB for sleep. Further, TIB $\geqslant 9 \mathrm{~h} \cdot$ night $^{-1}$ contributed alone to $20 \%$ of the variation of time spent in physical activity, and subjects with TIB $\geqslant 9 \mathrm{~h} \cdot$ night $^{-1}$ have $<3.3 \mathrm{~h}$ of physical activity per day than those with TIB $<9 \mathrm{~h} \cdot \mathrm{night}^{-1}$. Secondly, physically inactive patients had more fragmented sleep than those physically active and, when comparing patients according to sleep fragmentation, those with more fragmented sleep spent $10 \%$ less of 
TABLE 2 Clinical, sleep and physical activity in daily life according to sleep quantity

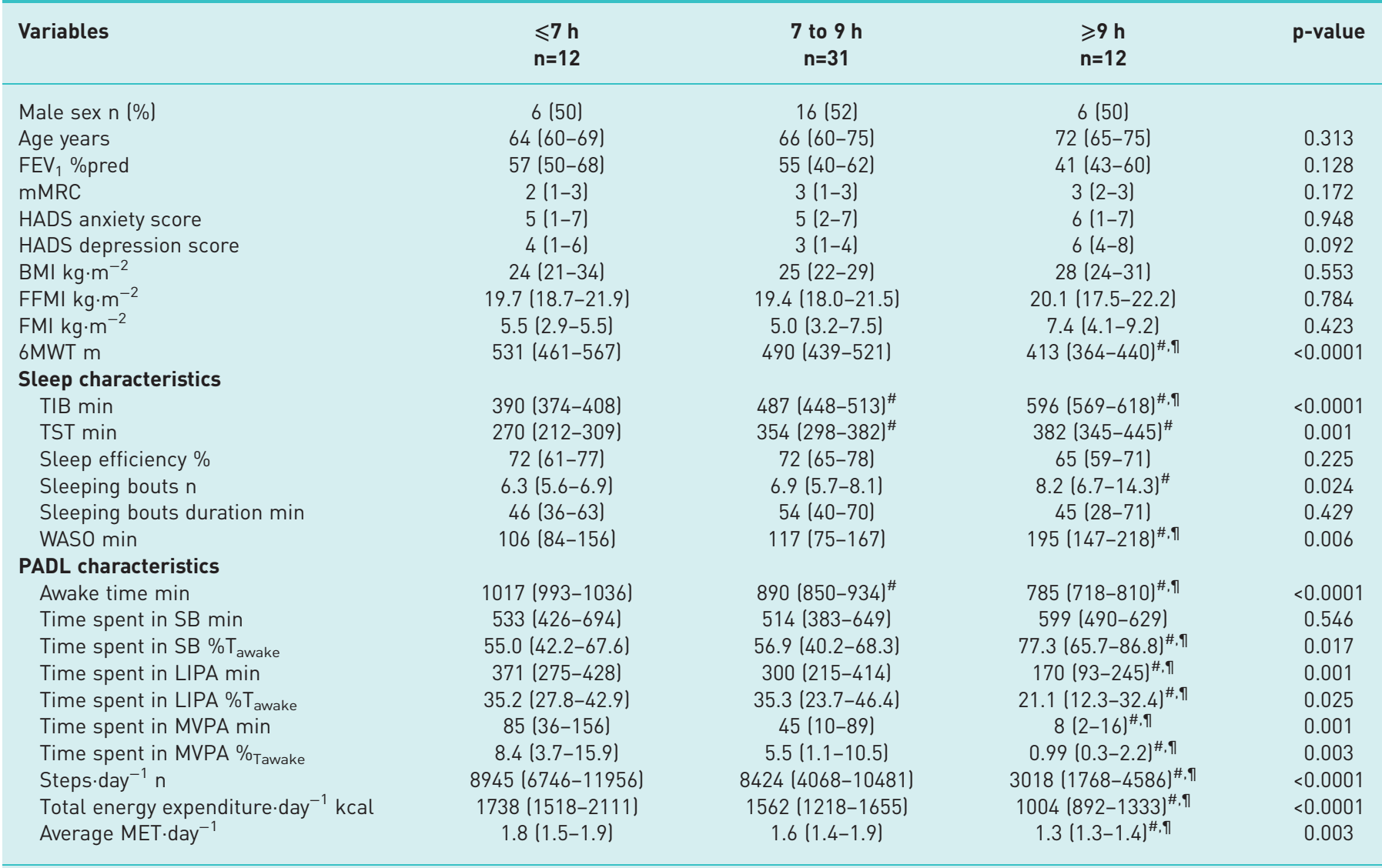

Data are presented as median (interquartile range), unless otherwise stated. FEV 1 : forced expiratory volume in the first second; mMRC: modified Medical Research Council; HADS: Hospital Anxiety and Depression Scale; BMI: body mass index; FFMI: fat-free mass index; FMI: fat mass index; 6MWT: 6-min walking test; TIB: total time in bed; TST: total sleep time; WASO: wake-after-sleep onset; PADL: physical activity in daily life; SB: sedentary behaviour; LIPA: light intensity physical activity; MVPA: moderate-to-vigorous physical activity; $T_{a w a k e}$ : time spent awake; MET: metabolic equivalents of task. ${ }^{\#}: p<0.05$ versus $\leqslant 7 \mathrm{~h} ;{ }^{\text {ๆ }}: \mathrm{p}<0.05$ versus 7 to $9 \mathrm{~h}$.

awake time on LIPA than patients with less sleep fragmentation. Finally, we also showed that male subjects with COPD presented the same quantity of sleep than female patients, but with considerably worse quality.

To our knowledge, this is the first time that both quantity and quality of sleep and their relationship with objective assessments of sedentary behaviour and PADL have been addressed in patients with COPD.

FIGURE 1 Proportion of time spent in SED behaviour, LIPA and MVPA lexpressed as a percentage of awake timel among groups according to sleep quality. SED: sedentary; LIPA: light intensity physical activity; MVPA: moderateto-vigorous physical activity. ${ }^{*}: p<0.05$.

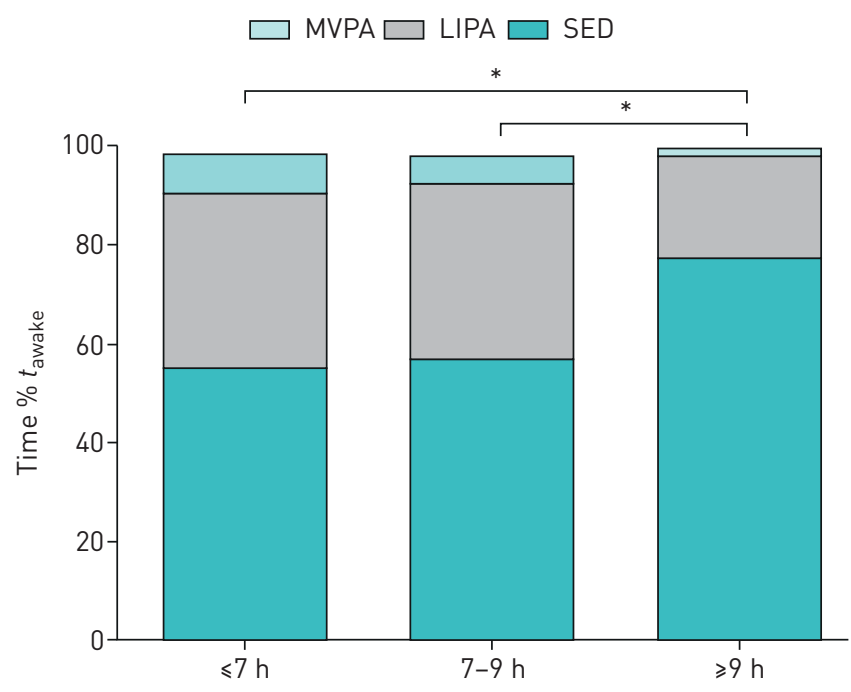



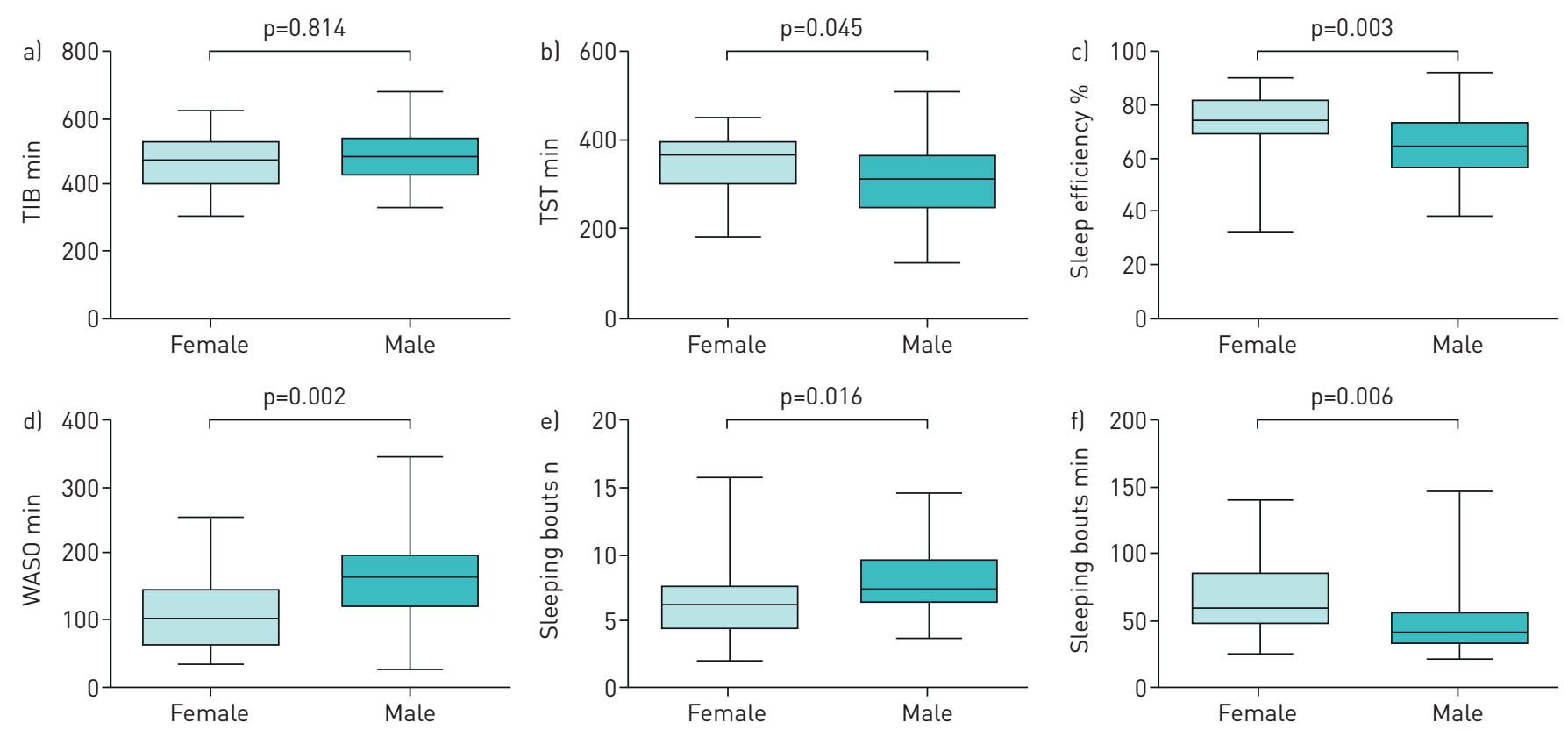

FIGURE 2 Sleep characteristics between female and male patients regarding a) total TIB, b) TST, c) sleep efficiency, d) WASO, e) number of sleeping bouts, and f) average duration of sleeping bouts. TIB: total time in bed; TST: total sleep time; WASO: wake time after sleep onset.

As previously mentioned, the leading sleep organisations recommend 7-9 $\mathrm{h}$ of sleep for adults and older adults $[9,10]$. It is worth noticing that the vast majority of evidence that supported these recommendations were derived from large cohort studies involving mostly self-reported measures. As clearly stated at the recommendation document [9], these subjective measures often describe total TIB rather than actual sleep time, and therefore the present study used TIB as outcome in order to be comparable with these reports from the literature. In the present study, $60 \%$ of the patients reached the recommended sleep quantity, whereas $20 \%$ spent $<7 \mathrm{~h}$ in bed and other $20 \%$ spent $\geqslant 9 \mathrm{~h}$ in bed for sleep. Evidently, the longer the time spent in bed for sleep at night the shorter will be the time available for physical activity during the day. Even after correction as a percentage of awake time, sedentary behaviour was still significantly higher in patients with TIB $\geqslant 9 \mathrm{~h}$ in comparison to both groups of patients with TIB $<9 \mathrm{~h}$. In fact, this group spent almost $80 \%$ of their awake time in sedentary behaviour. Likewise, time spent in LIPA and MVPA, as well as the number of steps were significantly lower in the group TIB $\geqslant 9 \mathrm{~h}$ than for the remaining subjects. These results suggest that sleeping longer than $9 \mathrm{~h} \cdot \mathrm{night}^{-1}$ does not lead to higher levels of PADL in patients with COPD; on the contrary, patients with this profile are more sedentary and less active. Interestingly, the group with TIB $\geqslant 9 \mathrm{~h}$ was characterised by a significantly worse 6MWT than the other groups, despite being similar with respect to sex, degree of airflow obstruction and anthropometric characteristics (table 2). Moreover, TIB $\geqslant 9 \mathrm{~h}$ overshadowed all other studied variables and was the only significant predictor of time spent in physical activity. The 6MWT, level of PADL and sedentary behaviour have been shown to be independent predictors of mortality in patients with COPD [3, 8,33 , which leads us to presume that patients who spend $\geqslant 9 \mathrm{~h}$ in bed per night are most severely affected in terms of health status and under higher risk than the others. Noteworthy, in older adults, there is evidence that long sleep duration per se is associated with greater mortality [34] even in individuals with better health status (i.e. good cognitive function, no depression and without limitations in activities of daily living) [35]. Therefore, the increase in mortality may not only be due to worse health status; long sleep duration itself can be considered an independent predictor of mortality [35].

Besides sleep quantity, another important aspect to be evaluated is sleep quality. Sleep complaints and night-time symptoms are frequent and have a detrimental impact on health status in patients with COPD $[14,36]$. Studies evaluating sleep quality in COPD were mostly subjective and also showed that impaired sleep quality may contribute to worse outcomes [13]. According to the recommendations, a WASO $\leqslant 20 \mathrm{~min}$ and sleep efficiency $\geqslant 85 \%$ indicate good sleep quality, while WASO $\geqslant 41 \mathrm{~min}$ and sleep efficiency $\leqslant 74 \%$ seem to indicate poor sleep quality in older adults [11]. In the present sample, only two $(3.6 \%)$ patients presented WASO $<41 \mathrm{~min}$ and no patient presented WASO $\leqslant 20 \mathrm{~min}$; moreover, almost all of the sample presented low sleep efficiency, with only four $(7.2 \%)$ patients presenting sleep efficiency $\geqslant 85 \%$. The present study showed that poor sleep quality is associated with both LIPA and MVPA, as patients with fragmented sleep spent less time in LIPA as well as patients considered inactive presented more 
fragmented sleep. When sleep quality was compared among groups classified by sleep quantity, patients with TIB $\geqslant 9 \mathrm{~h}$ presented significantly higher sleep fragmentation (higher number of sleeping bouts and higher WASO) than the remaining sample. These findings highlight the fact that sleep quantity does not mean sleep quality, which is an important information to keep in mind mainly when interpreting studies with subjectively measured sleep quantity.

Another finding of the present study is that objectively measured sleep quality was better in female than male patients with COPD, even though sleep quantity was similar between sexes. Women with COPD seem to be more symptomatic and present a worse health-related quality of life than male patients, which could influence self-perceived sleep quality [37]. When comparing subjective and objective quality of sleep in male and female subjects with and without COPD, there is evidence that, despite a higher prevalence of reported sleep disturbances in women, the association between COPD and impaired sleep was more evident in men [38]. SPINA et al. [19] showed that male subjects with COPD also presented worse objectively measured sleep quality than females. However, our study design and the multitude of factors which may play a pivotal role in this issue do not allow any causality to be inferred at this point. Despite the potential existence of sex differences related to behavioural, physiological and environmental factors, there is still a gap in the literature regarding mechanisms and differences in clinical presentation of COPD between sexes, including in terms of sleep quality.

This study has some strengths and limitations. Sleep and PADL were objectively evaluated, and all data from the activity monitor were analysed manually patient by patient and minute by minute. Although unfeasible for large samples, we believe this approach was a strength of the study, especially for maximal accuracy in the in-depth evaluation of sleep characteristics. A wide variation in bedtime and wake-up time was noticed in the patients, which could be misinterpreted with the use of algorithms with pre-determined windows for these analyses. Another strength of this study was the objective evaluation of sleep and PADL for a mean of 6.8 days, including the weekend, which allows a more comprehensive reflection of real habits concerning sleep and PADL. As for the limitations: patients were not assessed regarding sleep disorders, as there was no polysomnography/polygraphy available for this research project. Additionally, patients with more important sleep debt were not represented by our sample, with only two patients with TIB $<6 \mathrm{~h}$. Association between quantity of sleep and impairment related to deteriorated quality of wakefulness has a U-shape, with a marked increase when long sleep duration is $>9 \mathrm{~h}$ and short sleep duration is approximately $<5 \mathrm{~h}$ [39]. Then again, higher TIB may be a characteristic of patients with COPD, who are elderly, frequently retired and with considerable available time, and this may be the reason why we did not find any important differences in the group with TIB $\leqslant 7 \mathrm{~h}$. We also acknowledge that TIB may not be fully accurate for the measurement of sleep duration and that we were not able to study the role of characteristics such as working and marital status on sleep or PADL. Finally, the cross-sectional design of this study does not allow us to make any causality assumptions. Interventional and longitudinal studies, with larger samples and objective assessment of sleep, are needed to better understand its influence on improving PADL and sedentary behaviour in patients with COPD.

\section{Conclusion}

TIB $\geqslant 9$ h.night ${ }^{-1}$ is a determinant factor of objectively assessed level of physical activity in subjects with COPD. Patients with TIB $\geqslant 9 \mathrm{~h} \cdot$ night $^{-1}$ have more fragmented sleep, are more sedentary and less physically active than those with $<9 \mathrm{~h} \cdot$ night $^{-1}$, independently of the awake time. Moreover, sleep quantity does not necessarily mean sleep quality. Sleep quality is frequently poor especially in males, and is worse in patients classified as inactive. Increasing PADL and decreasing sedentary behaviour are challenging in these patients, and the quantity of sleep may be one of the keys to achieve these goals.

Author contributions: R.P. Hirata contributed to conceptualisation, methodology, formal analysis and writing the original draft of the manuscript; D.C. Dala Pola, L.P. Schneider and M.P. Bertoche contributed to methodology, data collection and visualisation of the work; K.C. Furlanetto contributed to data collection, formal analysis and critical review of the manuscript; N.A. Hernandes and A.E. Mesas contributed to formal analysis and critical review of the manuscript; and F. Pitta contributed to conceptualisation, coordination of the project as a whole, formal analysis and interpretation, writing the original draft and critical review of the manuscript. F. Pitta had full access to all the data and takes responsibility for the integrity of the work as a whole, from inception to published article.

Ethics approval: This study was approved by the local ethical committee (n.123/09) and written informed consent was obtained from all participants before study entry.

Conflict of interest: None declared.

Support statement: R.P. Hirata is supported by a personal scholarship from Conselho Naciconal de Desenvolvimento Científico e Tecnológico (CNPq), grant number 151647/2019-4; K.C. Furlanetto is supported by a personal grant from Fundação Nacional do Desenvolvimento do Ensino Superior Particular (FUNADESP), grant number 5301164; and 
F. Pitta and A.E. Mesas are supported by personal grants from Conselho Nacional de Desenvolvimento Científico e Tecnológico (CNPq), grant number 303131/2017-9.

\section{References}

1 Global Strategy for the Diagnosis, Management and Prevention of COPD, Global Initiative for Chronic Obstructive Lung Disease (GOLD) 2019. www.goldcopd.org

2 Watz H, Pitta F, Rochester CL, et al. An official European Respiratory Society statement on physical activity in COPD. Eur Respir J 2014; 44: 1521-1537.

3 Waschki B, Kirsten A, Holz O, et al. Physical activity is the strongest predictor of all-cause mortality in patients with COPD: a prospective cohort study. Chest 2011; 140: 331-342.

4 Pitta F, Troosters T, Spruit MA, et al. Characteristics of physical activities in daily life in chronic obstructive pulmonary disease. Am J Respir Crit Care Med 2005; 171: 972-977.

5 Schneider LP, Furlanetto KC, Rodrigues A, et al. Sedentary behaviour and physical inactivity in patients with chronic obstructive pulmonary disease: two sides of the same coin? COPD 2018; 15: 432-438.

6 Sedentary Behaviour Research N. Letter to the editor: standardized use of the terms 'sedentary' and 'sedentary behaviours'. Appl Physiol Nutr Metab 2012; 37: 540-542.

7 Garber CE, Blissmer B, Deschenes MR, et al. American College of Sports Medicine position stand. Quantity and quality of exercise for developing and maintaining cardiorespiratory, musculoskeletal, and neuromotor fitness in apparently healthy adults: guidance for prescribing exercise. Med Sci Sports Exerc 2011; 43: 1334-1359.

8 Furlanetto KC, Donaria L, Schneider LP, et al. Sedentary behavior is an independent predictor of mortality in subjects with COPD. Respir Care 2017; 62: 579-587.

9 Hirshkowitz M, Whiton K, Albert SM, et al. National Sleep Foundation's updated sleep duration recommendations: final report. Sleep Health 2015; 1: 233-243.

10 Consensus Conference Panel, Watson NF, Badr MS, et al. Joint Consensus Statement of the American Academy of Sleep Medicine and Sleep Research Society on the Recommended Amount of Sleep for a Healthy Adult: Methodology and Discussion. J Clin Sleep Med 2015; 11: 931-952.

11 Ohayon M, Wickwire EM, Hirshkowitz M, et al. National Sleep Foundation's sleep quality recommendations: first report. Sleep Health 2017; 3: 6-19.

12 Smith MT, McCrae CS, Cheung J, et al. Use of actigraphy for the evaluation of sleep disorders and circadian rhythm sleep-wake disorders: an American Academy of Sleep Medicine clinical practice guideline. J Clin Sleep Med 2018; 14: 1231-1237.

13 Shah NM, Murphy PB. Chronic obstructive pulmonary disease and sleep: an update on relevance, prevalence and management. Curr Opin Pulm Med 2018; 24: 561-568.

14 Agusti A, Hedner J, Marin JM, et al. Night-time symptoms: a forgotten dimension of COPD. Eur Respir Rev 2011, 20: 183-194.

15 Kinsman RA, Yaroush RA, Fernandez E, et al. Symptoms and experiences in chronic bronchitis and emphysema. Chest 1983; 83: 755-761.

16 Shorofsky M, Bourbeau J, Kimoff J, et al. Impaired sleep quality in COPD is associated with exacerbations: the CanCOLD Cohort study. Chest 2019; 156: 852-863.

17 Geiger-Brown J, Lindberg S, Krachman S, et al. Self-reported sleep quality and acute exacerbations of chronic obstructive pulmonary disease. Int J Chron Obstruct Pulmon Dis 2015; 10: 389-397.

18 Omachi TA, Blanc PD, Claman DM, et al. Disturbed sleep among COPD patients is longitudinally associated with mortality and adverse COPD outcomes. Sleep Med 2012; 13: 476-483.

19 Spina G, Spruit MA, Alison J, et al. Analysis of nocturnal actigraphic sleep measures in patients with COPD and their association with daytime physical activity. Thorax 2017; 72: 694-701.

20 Chen R, Tian JW, Zhou LQ, et al. The relationship between sleep quality and functional exercise capacity in COPD. Clin Respir J 2016; 10: 477-485.

21 Vardar-Yagli N, Saglam M, Savci S, et al. Impact of sleep quality on functional capacity, peripheral muscle strength and quality of life in patients with chronic obstructive pulmonary disease. Expert Rev Respir Med 2015; 9: 233-239.

22 Lewthwaite H, Effing TW, Olds T, et al. Physical activity, sedentary behaviour and sleep in COPD guidelines: A systematic review. Chron Respir Dis 2017; 14: 231-244.

23 Rodrigues A, Camillo CA, Furlanetto KC, et al. Cluster analysis identifying patients with COPD at high risk of 2-year all-cause mortality. Chron Respir Dis 2019; 16: 1479972318809452.

24 Hill K, Dolmage TE, Woon L, et al. Measurement properties of the SenseWear armband in adults with chronic obstructive pulmonary disease. Thorax 2010; 65: 486-491.

25 Patel SA, Benzo RP, Slivka WA, et al. Activity monitoring and energy expenditure in COPD patients: a validation study. COPD 2007; 4: 107-112.

26 O'Driscoll DM, Turton AR, Copland JM, et al. Energy expenditure in obstructive sleep apnoea: validation of a multiple physiological sensor for determination of sleep and wake. Sleep Breath 2013; 17: 139-146.

27 Pereira CA, Sato T, Rodrigues SC. New reference values for forced spirometry in white adults in Brazil. J Bras Pneumol 2007; 33: 397-406.

28 Miller MR, Crapo R, Hankinson J, et al. General considerations for lung function testing. Eur Respir J 2005; 26 $153-161$.

29 Holland AE, Spruit MA, Troosters T, et al. An official European Respiratory Society/American Thoracic Society technical standard: field walking tests in chronic respiratory disease. Eur Respir J 2014; 44: 1428-1446.

30 Britto RR, Probst VS, de Andrade AF, et al. Reference equations for the six-minute walk distance based on a Brazilian multicenter study. Braz J Phys Ther 2013; 17: 556-563.

31 Lukaski HC, Bolonchuk WW, Hall CB, et al. Validation of tetrapolar bioelectrical impedance method to assess human body composition. J Appl Physiol (1985) 1986; 60: 1327-1332.

32 Rutten EP, Spruit MA, Wouters EF. Critical view on diagnosing muscle wasting by single-frequency bio-electrical impedance in COPD. Respir Med 2010; 104: 91-98. 
33 Casanova C, Cote C, Marin JM, et al. Distance and oxygen desaturation during the 6-min walk test as predictors of long-term mortality in patients with COPD. Chest 2008; 134: 746-752.

34 da Silva AA, de Mello RG, Schaan CW, et al. Sleep duration and mortality in the elderly: a systematic review with meta-analysis. BMJ open 2016; 6: e008119.

35 Mesas AE, Lopez-Garcia E, Leon-Munoz LM, et al. Sleep duration and mortality according to health status in older adults. J Am Geriatr Soc 2010; 58: 1870-1877.

36 Ding B, Small M, Bergstrom G, et al. A cross-sectional survey of night-time symptoms and impact of sleep disturbance on symptoms and health status in patients with COPD. Int J Chron Obstruct Pulmon Dis 2017; 12: 589-599.

37 Aryal S, Diaz-Guzman E, Mannino DM. COPD and gender differences: an update. Transl Res 2013; 162: 208-218.

38 Theorell-Haglow J, Olafsdottir IS, Benediktsdottir B, et al. Sex differences in reported and objectively measured sleep in COPD. Int J Chron Obstruct Pulmon Dis 2016; 11: 151-160.

39 Ohayon MM, Reynolds CF 3rd, Dauvilliers Y. The link between excessive quantity of sleep and deteriorated quality of wakefulness - Implications for the DSM-5. Ann Neurol 2013; 73: 785-794. 